\title{
Taking the Forbidden Space: Graffiti and Resistance in Addis Ababa University, Ethiopia
}

\author{
Mulumebet Zenebe
}

\section{Introduction}

Pietrosanti suggests that graffiti is about "taking spaces otherwise forbidden" $(2010,72)$, while Ferrell (1995) states that young men and women employ graffiti as a means of resisting particular constellations of political and religious authorities. In this chapter, graffiti around the University of Addis Ababa campus is studied as a form of the writers' self-expression. In research on graffiti, the graffiti artist is seen as negotiating a myriad of conflicted relationships between seen and unseen, space and place, local and global, and quiet and loud. Graffiti has also been interpreted as having the potential to communicate the common visions of politics that the young talk about with each other, and that unite people as members of a larger community, both local and global (Truman 2010, 10). What can the silent drawings on Ethiopian university walls and tables reveal to a researcher on youth and politics?

Ajayi argues that the capacity for independent thought and expression has not been encouraged in African countries and, consequently, students in African universities pay a heavy price for free expression (Ajayi cited in Balsvik 2007, 3). In this regard, Addis Ababa University is no different from the higher education institutions of other African countries. Established in the 1950s, it is one of the oldest and largest universities in Africa yet, with regards to freedom of expression, the previous and current regimes of Ethiopia can be regarded as repressive and, as Balsvik $(2007,2)$ observes, "Since the universities are key state institutions, conditions for free expression even within the university campuses are highly dependent on the actions and reactions of the regimes in power."

The repressive environment in Ethiopia encourages students to opt for hidden forms of expression. Since the establishment of the university, students have not been encouraged to write on topics like politics and religion. For example, in one of the first rounds of Addis Ababa University student papers known as UC Calls, students were encouraged to "write on any topic under the sun, except on politics and religion" (Bahru 2014, 78); pseudonyms were 
a common feature of student publications, with writers using pen names such as "Temariw" (the Student), "Lelaw Temari" (the Other Student) and "Teyaqiw" (the Enquirer) (Bahru 2014, 79). Although there were changes over the years and the university made a significant contribution to the student movement in Ethiopia, students still prefer to use hidden forms of expression to air their views, especially on certain issues that are considered sensitive and controversial. Graffiti, often associated with resistance and rebellion (Nielenberg 1994), combines different linguistic and artistic forms to express messages of a personal and social nature. It is a form situated between visual and verbal expression that often reveals something about the lives, relationships and identities of those who produce it (Pietrosanti 2010, 1). With reference to Addis Ababa University, Balsvik states that " $\mathrm{t}]$ he conditions for creating, practicing and developing a political culture of dialogue and openness in Addis Ababa University from the 1960 s until the turn of the century were discouraging" $(2007,177)$, and it is mainly due to this lack of freedom that young people opt for anonymity when expressing themselves.

This chapter examines the various ways in which the youth at Addis Ababa University express their concerns through graffiti and, specifically, the lived dynamics of graffiti production in the context of legal and political power and social control. A major question that the paper explores is the type of authority the graffiti is attempting to resist, thereby invoking the larger cultural and political context in which the graffiti at the university proliferates. Peteet (1996, 155) writes that " $\mathrm{g}] \mathrm{raffiti}$ should be contextualized in sets of power relations and structures and the forms of resistance these entail"; therefore, in order to derive meaning from a particular work, it is necessary to examine the context in which the graffiti appears. Another focus of the chapter are the interactions through which writers surprise and challenge one another. In some of the graffiti, two or more writers appear to exchange words in the form of a dialogue, although, since the graffitists work in private, it is difficult to be certain whether they are one or multiple individuals. While dialogue would suggest different writers, particularly when opposing ideas are exchanged, it is possible that a single person has used the format to try to convince the reader that a conversation took place. Finally, while the chapter pays attention to the particular meanings of authority and resistance in the everyday experience of the university students, it is important to note that the graffiti artists do not present a unified voice, and not all graffiti is progressive.

The methodological framework for the examination of graffiti writing at Addis Ababa University incorporates observation and document research. The graffiti in the main campus, which has the largest number of students and hosts the major activities of the university, was collected from 2014 to 2016 
from the walls of the university libraries, toilets and class rooms, and from girls' dormitories with the help of female students. Furthermore, the writer has used her Addis Ababa University graffiti collection from 1997.

Most of the graffiti at the university consists of words and statements written in the local language, Amharic, and English, sometimes with the addition of drawings to illustrate the writers' points. For example, the female body would mostly be drawn next to a message about women in general and female sexuality in particular. All the graffiti used in this chapter written in Amharic has been translated into English.

\section{Resisting Authority}

The major message of the graffiti in the main campus is resistance to authority: the writers have reached out to their desired audience to communicate antiestablishment ideas. As mentioned above, there are certain subjects students are not encouraged to write about, yet the majority of recorded graffiti was in the form of written statements. This suggests that advancing a certain ideology is a key intention of graffiti at Addis Ababa University, with graffiti writers putting forward their opinions and perspectives on an issue considered important but usually controversial. "Graffiti, then, are little insights, little peepholes into the minds of individuals who are spokesmen not only for themselves but for others like them" (Reisner 1971). Yet it is important to note that graffiti scribblings do not only comprise resistance messages but also present other social issues. As Zakareviciute $(\mathbf{2 0 1 4}, \mathbf{1 0 9})$ observes:

Although approaching graffiti as the dominated's resistance against the dominator indeed explains a wide realm of this societal conduct, it nevertheless regards graffiti only as pro or counter statement. Therefore quite often, significant side-meanings and social perceptions on various issues are omitted.

The graffiti writers at Addis Ababa University express their opinions privately but in public and we may assume that these are opinions they would not dare to offer in person. Three strongly pronounced themes emerge: sexuality, religion and politics; in the Ethiopian cultural and political context all the three are considered highly sensitive. The most common theme, sexuality, mainly consisted of statements related to female sexuality. Religious and anti-religious statements were frequent. Derogatory statements about some ethnic groups were also observed. 


\section{Sexuality}

Graffiti is said to be subversive as it presents issues like sexuality which are considered taboo (Nielenberg 1994); therefore, it is not surprising that sexuality is so common in graffiti since it has been one of the most avoided subjects in public conversation (Reisner 1971), not least in Ethiopia where the subject of sex is publicly shrouded in silence (Rachel 2001, 3). Talking about sex in public is considered culturally taboo as Ethiopian tradition demands chewanet (decency). Rather, in Ethiopia, oral literature - the commonest mode of transmitting the deeply entrenched norms of society - is a significant means of expression of sexuality and related matters, and thoughts and attitudes are more freely expressed in this medium than in formal settings and languages. People express their feelings and emotions without much reservation through oral and written literature and, concomitantly, it has been suggested that graffiti's sexual content could provide insight into the extent and nature of people's suppressed sexual desires (Trahan 2011).

The graffiti writers at Addis Ababa University defy the norm and write about sexual matters that are not openly mentioned or discussed on walls and tables. Frequently, responses appear below the original messages so that viewers can read the graffiti dialogue as it occurs over time. In some instances the first writer is supported by the second who tries to add to what the first writer said and/ or include some words of appreciation. Some of the writers draw or describe genitals in an exaggerated manner. Others would like the readers to know that sex is important, as elaborated on these graffiti written on a classroom wall and a library reading table:

\section{No Sex - No Life}

The way to heaven is sex.

It is only when we look at the context in which the graffiti appears that we realize that the writers are resisting what is considered normal. In a country like Ethiopia where religion plays a major role in organizing people's lives, stating that sex is the way to heaven is total subversion. Furthermore, it is believed that engaging with sexual matters places people outside the boundaries of morality, making them unstable. While the norm strictly endorses religious rules and rituals; the writers of the above graffiti openly declare the opposite.

Parents interviewed in the capital, Addis Ababa, stated that they would take serious measures if they found out that their daughters were having sexual relationships with men (Mulumebet 2006). Both religion and Ethiopian tradition and society are extremely repressive regarding sexual expression, 
especially women's sexual expression (e.g. Rachel 2001) and the graffitists at the university are writing in an environment where discussion about sexual matters is restricted. "Since the inscriptions are anonymous, and located in restricted, hidden, or remote places, they must be done by those who wouldn't dare express their erotic interests openly where they could be identified" (Reisner 1971). It is common to find writings expressing interest to have sexual relations as shown in the following two graffiti written on library reading tables:

Women who would like to have sex with me, please call me.

I would like to have a boyfriend and have sex with him.

Response: I am interested. Please write me with the following email address

This response endorses the original writer's graffiti, but it is observable that some responses to graffiti with sexual content take the form of criticism, mainly stressing that indulgence in sexual matters is immoral. Those who criticize the original writers usually give religious reasons because, in many instances, religious morality and sexual morality are considered the same. The need to control sexual desire and not to fall into the trap of Siga (the flesh) is emphasized as it is considered that suppressing sexual feelings is a way to protect oneself from the evils of the world. As Foucault (1978) notes, in Christian doctrine more generally the pleasures of the flesh are regarded as evil and sinful and should be renounced.

Most young students leave their families for the first time when they go to university and, while they were living with their parents, they rarely discussed sexual matters. This ban does not only apply to sexuality; children are not allowed to speak out in other areas either. The many Ethiopian sayings and jokes about children's ignorance and the importance of silencing them illustrate this. In Ethiopia, parent-child relationships are very formal and authoritarian and children's opinions are rarely sought (Mulumebet 2006). Indeed, there is a surprisingly similar attitude to child sexuality as in Foucault's reading of the European Victorian period:

Everyone knew, for example, that children had no sex, which was why they were forbidden to talk about it, why one closed one's eyes and stopped one's ears whenever they came to show evidence to the contrary, and why a general and studied silence was imposed $(1978,4)$.

The main reason for silencing childhood sexuality is to control. 
Young men and women in Ethiopia are not enthusiastic about discussing sexual matters with parents and family members but girls disapprove of these discussions more than boys (Taffa et al. 1999 cited in Getnet 2009). Then, in contrast with their childhoods, young men and women in Ethiopian universities have the new experience of being able to discuss sexual matters, and graffiti and jokes are two of the media widely used for this. The graffiti writings on sexual matters are not, however, merely subversive: they mainly focus on women's sexuality, depicting women's sexual bodies negatively as unclean and unpleasant. Next to the descriptions, there are sometimes drawings portraying the human genitals or other sexual organs, and responses either criticizing the writers or showing appreciation for their open descriptions. The following two graffiti are examples of the negative depiction of women's sexual bodies:

Even if the vagina is ugly, we still continue having sex.

Women, you should know your vagina is not clean.

This negative portrayal of women's sexuality can also be seen in the way women's sexual organs are depicted in society. In Ethiopia, not only graffiti but jokes and oral poems also depict the sexuality of women as unpleasant (Mulumebet 2006), a negative perception that must be seen in relation to women's position in society. In Ethiopia, women's sexual organs and women's blood are considered unclean. In some parts of the country, women give birth unattended in an isolated hut built for the purpose because the place where women deliver their babies and everything in it is considered unclean (Meseret 2011). Hence, a man who entered the room would not be allowed to enter the church (Pankhurst 1990, 267). By the same token, parents interviewed about their children's sexual relationships said that it is more important to control girls than boys. As some said, it is appropriate to tolerate male sexual transgression as they have stronger sexual needs than women (Mulumebet 2006).

These deep-rooted negative attitudes towards women are the major causes of the inequality between the sexes which materializes in the challenges constraining women's equal participation in the social, economic and political spheres of the country (Gennet 2014: Alem 2008). The same applies to female students in Ethiopian universities. Compared to male students, female students perform less well in their studies, and harassment of, and violence against, female students is very common. The gender stereotypes that push female students to behave in a traditional manner are clearly rife even on campus, as evidenced by the graffiti on the subject. This was said to be very disturbing and upsetting for female students (FAWE 2010, 114) as it is mainly 
women's sexual bodies that are portrayed negatively. While the vagina is depicted as unclean, the penis is mostly described in relation to its size, particularly the correlation of increased size with aggressive sex and women's interest in having sex with men with big penises. This different depiction of the sexual organs of men and women is a clear indication of the society's double standard in relation to men's and women's sexuality as exemplified by the following:

Glory and Praise to King Penis!!

Let it live as the king of vagina forever!

Response: AMEN!!

It should be noted that, although the majority of the graffiti depicts men positively, according to a study in a number of public universities in Ethiopia some graffiti in female students' dormitories portrays men as unfaithful and untrustworthy (Teshome 2016).

In Ethiopia, the taboo does not only apply to sex and sexual pleasure; there are also restrictions on talk about sexual relationships and romance. Expressing love verbally is regarded as indecent. Students from all over the country come to the university and those from rural parts of Ethiopia in particular find it extremely difficult to talk openly about romantic feelings. Similarly, Sememen, one of the most popular Ethiopian novels, vividly depicted the challenges university students from rural Ethiopia face in connection with romantic relationships. In this closed environment, the following graffiti writer expresses his feelings about sexual relationship and love and seems to expect a response from readers:

I am in love with a girl.

Response a: Commit suicide.

Response $b$ : Be a man and ask her.

Response c: Focus on your study.

If you want to discuss about love, please email me at gxxx@postmaster .com.

Both of the above graffiti were written on a toilet wall. Some writers ask for advice and others merely want a response. Thus, viewers can read the graffiti dialogue as it occurs over time. Yet, from the way original statements are expressed, it seems that most of the writers do not expect a real response, putting telephone numbers and email addresses which do not seem to be valid. 
Women as well as men express their feelings on the theme of romantic love as the following two statements written on a library reading table indicate:

I am suffering because I am in love with a man.

I am happy he started to love me back after two years.

In the above graffiti, however, it is not possible to be absolutely certain about the gender of the writers. From their content they appear to be written by women, but one cannot rule out the possibility of men, or a men pretending to be women. As Reisner $(1971,4)$ writes:

Despite the prevalence of the fruits of their efforts, writers of graffiti are seldom seen at their labors. So, if we ask what type of individuals writes graffiti, the answer lies in the nature of the message, the place where it is written, and the spirit of the times.

Women graffiti writers at Addis Ababa University are resisting the norm that they should be silent about sexual issues. Although Ethiopian women face a number of challenges, evidence shows that they are not passive victims but try to resist oppression by various means. For example, Ethiopian women share with each other experiences about sexual relationships (see Mulumebet and Flemmen 2008) while, in a similar vein, Signe Arnfred (2004:23) argues that "the notion of 'universal female subordination' is misplaced in Africa", giving the example of the phenomenon of women choosing not to marry. Furthermore, African women have always resisted the oppression of traditional rulers.

\section{Religion}

Another issue that is repeatedly addressed in the graffiti of Addis Ababa University is religion. Again, we need to look at the context in order to clearly understand the reason for this predominance. Students of the university come from all regions of Ethiopia, bringing their own cultures and religion and the important place religion has in their lives is clearly exhibited in the large quantity of graffiti on the subject. Most of the religious messages are short declaratory statements such as "Jesus is lord", with the writers advocating their own religious ideology. Moreover, there are dialogues between the followers of different Christian sects, principally between Ethiopian Orthodox Church followers and Protestants. 
Ethiopians are known for their deep religiosity (Molvaer 1980), historically being defenders of the faith rather than mere followers, as noted by Messay (1999, 111): "The wider the expansion of Islam and the consequent isolation of the Ethiopians, the deeper was their impression of being the last stronghold of Christianity, which stronghold had to withstand at all costs." One of the crucial institutions that has guided Ethiopia's history is the Ethiopian Orthodox Church, the oldest national church in Africa (Belay 1992). Although both Christianity and Islam are widely followed in Ethiopia, Orthodox Christianity is the oldest and most dominant religion in the country and its religious influence can be clearly observed in the day-to-day activities of the people. Christianity emerged in Ethiopia in the mid-fourth century, possibly earlier, and gained an important role in Ethiopian life that has lasted to the present; the Orthodox, so-called Tewahedo Church is deeply rooted in Ethiopian history, social life and ethics (Abbink 2003, 2).

Following religious rules and rituals is appropriate and sometimes mandatory in order to fit into the social system (Bahiru 2002, 8) and it is in this very religious environment that graffitists communicate ideas against the establishment and criticize religion. The following three graffiti were written on classroom wall and reading tables at a library:

Jesus is lord!

Response $a$ : Who said he is a thief?

Response b: One can't make jokes about the words of God.

Jesus will come back to this world. You need to receive Him and be saved. Response: He could come but he would be crucified and returned as usual! I can kill through Christ.

As we can see from the above graffiti, the writers question the authority of religion, which is also observable in the joke one respondent makes about Jesus and his crucifixion. In the third example the writer changed the popular Bible verse, "I can do whatever I need to do in life through Christ", to, "I can kill through Christ". For an Ethiopian Christian, making jokes about the word of God is considered a serious offence. Furthermore, the church is still a powerful institution in society more broadly (Bourdieu 2001, 116). When twentieth-century Ethiopian rulers tried to build a modern country out of a multi-cultural and multi-religious society, they used the institution of the church, specifically Orthodox Christianity, to promote a modern national identity. For example, Emperor Haile-Selassie, who ruled Ethiopia from 1930 to 1974, sought to build a modern national state within a framework of "religious uniformity" under the Orthodox Church (Wudu 2003, 89). Hence, for the graffiti writer, criticizing 
religion can, in the Ethiopian context, be read as offering resistance to the dominant power in the country.

According to some writers, however, the Church failed to play a significant role in bringing about national unity. "The Ethiopian Orthodox Church was an obstacle to secularization, modern changes, and, importantly, to the emergence of an inclusive national identity," writes Wudu (2003, 96), claiming that the attempt to create religious uniformity under the Orthodox Church marginalized other cultural, religious and linguistic groups in Ethiopia (Wudu 2003). This may be observed in the long lasting tension between the followers of different Christian sects. For example, one of the first Ethiopian reformist intellectuals of the early twentieth century, Hiruy Wolde Sellassie, urged the reform of the Orthodox Church as an imperative necessity if the challenges of Protestantism were to be withstood (Bahru 2014, 161). In a similar vein, graffiti writers of the present try to challenge the Orthodox Christianity's religious rules and rituals by citing different verses from the Bible while some of the graffiti at Addis Ababa University highlights the tension between Orthodox Christians and Protestants.

Orthodox - The real Faith.

Response a: All except Protestants worship idols.

Response $b$ : You are a newcomer.

In the first snippet, the Orthodox believer states that his/her religion is the real one, implying that other religions are wrong. The response is that the right religion is Protestantism and others worship idols, a critique which seems to be directed at Orthodox Christianity with its tradition of having the symbol of the Arc of the Covenant in churches. Then the first writer, or possibly another person with similar writing, responds stating that Protestants are newcomers, thereby claiming that his/her religion is the oldest. Abbink notes that the tension between religions is not new; Ethiopian Orthodox Christianity has "from its inception ... contended with other faiths: not only with indigenous religions and cults but also with Islam since the 7 th century and with Western forms of Christianity" (Abbink 2003, 2).

It is quite obvious that the current global environment intensifies the tension between the major religions in Ethiopia. According to Abbink, "the externally supported missionary educational institutions and local churches connected to them, as well as Islamic movements and groups financed from outside" force Ethiopian Orthodox Christianity to assert itself $(2003,4)$. Recently, conflicts among religions, between religions and the state and within religions have 
intensified (Karbo 2013, 52). The graffiti at Addis Ababa University depicts this same conflict as it is shown in the following two unconnected writings:

People, do not make a mistake by kissing a Church wall.

Salvation is only through Jesus Christ.

Here, the Protestant graffitist criticizes one of the major rituals in Orthodox Christianity, that of followers' kissing the walls when entering the premises of the holy place - a religious practice that has always been considered as a wrong practice by followers of Protestant religions. In the graffiti, the writer advises those who kiss the walls of the Orthodox Church to avoid the practice and follow the right path which is Jesus Christ. Another major issue of contention is the special place Saint Mary has in Ethiopian Orthodox Christianity. Some writers emphasized the importance of focusing on Jesus rather than Saint Mary.

Jesus is Lord!

Response: The Virgin Mary is His mother!

Some of the writings specifically focus on the religious elements that separate the Ethiopian Orthodox Christianity from other Christian religions. The Ethiopian Orthodox Church is known by its name "Tewahedo" (oneness), a name based on its Biblical Cannon. Unlike Christians who believe Christ to have two distinct natures, one divine and one human, followers of Orthodox Christianity in Ethiopia believe Christ has a divine nature in which his human nature is contained. Ethiopian Orthodox Christianity has its peculiar indigenized form, with significant Judaic influences (Belay 1992; Berhanu 2000; Pankhurst 1992; Ullendorff 1965). In terms of international graffiti comparison it is interesting and unusual that Ethiopian graffiti deals with theological specifics, but this is revealing of the societal divisions and power relations in the country.

\section{Politics}

The third theme that is widely observed in the graffiti of Addis Ababa University is politics, ethnic tension and conflict. Previous studies of graffiti at the university showed that most of the writings on the walls have explicitly political messages (Mulumebet 1998). Due to the repressive nature of Ethiopian regimes, freedom of political expression has been restricted both in and 
outside the university. In her study of the history of the student movement in Ethiopia, Randi Balsevik writes: "Opposition was interpreted as insurrection, as rebellion, and was considered to be against the cosmological order of things, disturbing deep cultural strands of reverence for authority" (2007, 177). It is in this environment that the graffiti writers express their dissatisfaction with the politics of the ruling party in the government and emphasize the need for change, specifically for unity and solidarity.

\author{
Does Democracy exist in Ethiopia? \\ Response: Never, Ever, Forever! \\ In previous times it was about the prosperity of Ethiopia. \\ Now it is about the destruction of Ethiopia.
}

These two pieces of graffiti show the dissatisfaction of the writers with the policies of the current government of Ethiopia: in the first, the government is criticized for repressing the democratic rights of the people of Ethiopia; in the second, the writer accuses the government of playing a destructive role compared with the previous regimes of Ethiopia. Graffiti in these instances has both political and social significance (Pietrosanti 2010, 55).

Ethiopian ethnic federalism and the recognition of the right to selfdetermination up to and including secession are designed to avoid ethnic domination. Although ethnic and cultural rights were accorded by the relevant legislation, the classification of Ethiopians primarily in terms of ethnicity and the strong territorialization of groups has given rise to new ethnic conflicts and border disputes. Hence, since 1991 ethnicity has become the most debated issue in Ethiopian politics (Abbink 2011; Institute of Peace and Security Studies 2011, 11; Zahorik 2014, 1; Karbo 2013, 43). The following three graffiti indicate the increased salience of ethnic divisions:

Who is better than a Gonderie?

Response: You are a monster because you are narrow minded and tribalist. Ethiopia has been divided by Woyane into small regions.

Response: Let Ethiopia be divided into small towns, rather than regions. That is Ethiopia's problem.

We strictly oppose ethnic politics since it has no use for our nation.

In most of the graffiti about ethnicity the denigration of, and prejudice against, certain groups by others can be clearly observed. The first piece shows how certain groups consider themselves better than others and the response 
indicates one person's reaction to this stance. The other two oppose ethnic politics in general and indirectly prescribe national unity for the nation. Indeed, as Vaughan $(2003,26)$ notes: "There is no other single issue in Ethiopian politics as inflammatory and controversial as the 'empowerment of ethnicity', and the 'self-determination of nations, nationalities and peoples".

Graffiti writers do not only offer resistance to existing structures but also propose alternative and better arrangements (Ferrell 1995). Ethnic federalism has been criticized for privileging ethnicity over other markers of identity like religion, class and gender, particularly given that, depending on the context, other ways of self-identification are sometimes more important than ethnicity. It is feared that the significant internalization of ethnic identities enhances mutual stereotyping and prejudice in Ethiopia (Abbink 2011, 611-612) and, indeed, most ethnic graffiti on the campus was written in the form of hate messages. In response to these messages, however, some graffiti writers encourage unity and solidarity. In the past, Addis Ababa University students fought for political freedom. "They demanded freedom of expression and assembly not only to prepare themselves for a future role as responsible citizens, but also to raise the level of political consciousness in the Ethiopian population" (Balsvik, 2005, 311). Using graffiti as a medium, students of Addis Ababa University still express their belief in the possibilities of fruitful change in Ethiopia.

\section{Concluding Remarks}

The chapter has explored the various ways in which graffiti writers in Addis Ababa University attempt to resist the control of the authorities, and has briefly examined the context of social control and political power in which the graffiti was produced. The major themes in graffiti at the university are associated with sexuality, religion, political power, ethnic differences and conflict. The graffitists have tried to reach a desired audience and communicate ideas that run counter to those of the establishment, but they have also tried to concretize or defend existing, perhaps threatened, dominant ideas, especially in terms of sexuality, religion and ethnicity. The university graffiti also incorporates interaction in which writers surprise and challenge one another. Ultimately, the writings remind us to pay attention to the particular meanings of resistance and authority in the everyday experience of youth.

The history of the Ethiopian state has been characterized as one of conflict, with varying dimensions based on class, ethnic, religious and regional sentiments. The graffiti writings analysed in this chapter are a clear indication 
of the intensification of these conflicts. The discussion does not only show how sexual, ethnic and religious identities can evoke deep divisions, but suggests that it is important to pay attention to the intersections of the three categories.

Though this chapter focused on the local issues presented in Addis Ababa University graffiti, it is important to examine how the writings relate to both the global graffiti subculture and the outside world. Ethiopian youth are not free from globalizing influences; hence, it is also important to look at their political engagement in the context of global social, economic and political transformations.

\section{References}

Abbink, Jon. 2003. A Bibliography on Christianity in Ethiopia. ASC Working Paper 52/2003, Leiden: African Studies Centre.

Abbink, Jon. 2011. "Ethnic-based federalism and ethnicity in Ethiopia: reassessing the experiment after 20 years." Journal of Eastern African Studies 5 (4): 596-618.

Alem, Desta. 2008. Candace: Invincible Women of Ethiopia. Ethiopian Millennium Foundation (SEM). Amsterdam.

Arnfred, Signe. 2004. "African Sexuality'/ Sexualities in Africa: Tales and Silences'” In Re-thinking Sexualities in Africa, edited by Signe Arndfred. Sweden: Almqvist and Wiksell Tryckeri.

Bahru, Zewde. 2014. The Quest for Socialist Utopia: The Ethiopian Student Movement $c$. 1960- 1974. Addis Ababa: Addis Ababa University Press.

Balsvik, Randi. 2005. Haile Sellassie's Students: The Intellectual and Social Background to Revolution, 1952-1974. Addis Ababa: Addis Ababa University Press.

Balsvik, Randi. 2007. The Quest for Expression: The State and the University in Ethiopia under Three Regimes, 1952-2005. Addis Ababa : Addis Ababa University Press.

Belay Giday. 1992. Ethiopian Civilization. Addis Ababa.

Berhanu Gobena. 200o. Amde Haimanot. Addis Ababa: Africa Printing Press.

Bourdieu, Pierre. 2001. Masculine Domination. Cambridge: Polity Press.

Ferrell, Jeff. 1995. "Urban graffiti: Crime, control, and resistance." Youth and Society 27 (1): $73^{-92 .}$

Forum for African Women Educationalists. 2010. "Female Students in Higher Education Institutions in Ethiopia: Challenges and Coping Strategies." In Strengthening Gender Research to Improve Girls' and Women's Education in Africa. FAWE Research Series, Vol. 1.

Foucault, Michael. 1978.The History of Sexuality. Volume 1 (Translated by Robert Hurley). London: Penguin Books. 
Gennet, Zewdie. 2014. Resistance, Freedom and Empowerment: The Ethiopian Women's Struggle. New Delhi: Concept Publishing.

Getnet, Tizazu. 2009. "Self- Reported Sexual Experiences, Sexual Conduct and Safersex Practices of Ethiopian Undergraduate Male and Female Students in the Context of HIV/AIDS Pandemic." PhD diss., State University of New York at Buffalo, New York.

Institute of Peace and Security Studies. 2011. An Anthology of Peace and Security Research. Vol. II. Addis Ababa University.

Karbo, Tony. 2013. Religion and social cohesion in Ethiopia. In International Journal of Peace and Development Studies 4 (3): 43-52.

Meseret, Tsige. 2011. "Isolating Women at times of Labour and Reproductive Health Outcomes: the Case of Mandura, North West Ethiopia". Master's Thesis, Institute of Gender Studies, Addis Ababa University, Addis Ababa.

Messay, Kebede. 1999. Survival and Modernization of Ethiopia's Enigmatic Present: A Philosophical Discourse. Asmara: The Red Sea Press, Inc.

Molvaer, Rnut Molvaer. 1980. Tradition and Change in Ethiopia: Social and Cultura Life as Reflected in Amharic Fictional Literature. Leiden: E.J. Brill.

Mulumebet, Zenebe. 1998. Graffiti in Addis Ababa University (Main Campus). A Paper Presented at the 1oth Annual Conference of Language Studies, Addis Ababa.

Mulumebet, Zenebe. 2006. "Negotiating Gender and Sexuality in the HIV/AIDS Discourse in Addis Ababa, Ethiopia: Contradictions and Paradoxes." PhD diss., University of Tromsø, Tromsø.

Mulumebet, Zenebe, and Anne Britt Flemmen. 2008. "Gender Relations and Sexual Norms in the HIV/AIDS Discourse in Addis Ababa. Focus on Women's Resistance." In, Urban Poverty in Ethiopia: The Economic and Social Adaptations of Women in Addis Ababa, edited by Emebet Mulugeta. Addis Ababa: Addis Ababa University Press.

Nielenberg, Jess. 1994. Proverbs in Graffiti: Taunting Traditional Wisdom. In Wise Words: Essays on the Proverb, edited by Wolfgang Mieder. New York: Garland Publishing Inc.

Pankhurst, Helen. 1992. Gender, Development and Identity: An Ethiopian Study. London: ZED books.

Pankhurst, Richard. 1990. A Social History of Ethiopia. Addis Ababa: AAU Printing Press.

Peteet, Julie. 1996. "The Writing on the Walls: The Graffiti of the Intifada." Cultural Anthropology 11 (2), 139-159.

Pietrosanti, Silvia. 2010. "Behind the tag: A journey with the graffiti writers of European walls." Master's thesis, University of Amsterdam.

Rachel, Lucas. 2001. "Sex, Sexuality, and the Meaning of AIDS in Addis Ababa, Ethiopia." PhD diss., University of Michigan, Ann Arbor. 
Reisner, Robert. 1971. Graffiti: Two Thousand Years of Wall Writing. New York: Book Company Inc.

Taffa, Negussie., R., Desalegn, S., Tesfaye, A., \& Mohammed, K. 1999. Do Parents and Young People Communicate on Sexual Matters? The Situation of Family Life Education (FLE) in a Rural Town in Ethiopia. Ethiopian Journal of Health Development. 13(3), 205-210.

Teshome, Mengesha. 2016. "A Psychological and Intersectional Examination of SocioPolitical Issues Reflected in Graffiti: Selected Public Universities in Focus." PhD Dissertation, Department of Foreign Languages and Literature, College of Humanities, Language Studies, and Journalism and Communication, Addis Ababa University.

Trahan, Adam. 2011. Identity and Ideology: the Dialogic Nature of Latrinalia. Internet Journal of Criminology. http://www.internetjournalofcriminology.com/Trahan _Identity_and_Ideology_The\%2oDialogic_Nature_of_Latrinalia_IJC_September _2011.pdf (accessed January 27, 2017).

Truman, Emily J. 2010. "The (In)Visible Artist: Stencil Graffiti, Activist Art, and the Value of Visual Public Space". In Queen's Journal of Visual \& Material Culture No. 3.

Ullendorff, Edward. 1965. The Ethiopians: An Introduction to Country and People. London: Oxford University Press.

Vaughan, Sarah. 2003. "Ethnicity and Power in Ethiopia." PhD diss., The University of Edinburgh.

Wudu Tafete. 2003. "Church, Nation and State: The Making of Modern Ethiopia, 1926-1991 - A Research Proposal." In Ethiopian Journal of the Social Sciences and Humanities 1 (1): 89-103.

Záhořík, Jan. 2014. Federalism and Ethnic Conflict in Ethiopia: A Comparative Regional Study by Asnake Kefale. EJSSLS, 1 (1): 98-100.

Zakareviciute, Ieva. 2014. "Reading Revolution on the Walls: Cairo Graffiti as an Emerging Public Sphere". Hemispheres, 29 (2): 110-127. 